\title{
Fuat Sezgin'in Eserinde Tasavvuf Literatürü Hakkında Bir Değerlendirme veya Gecikmiş Bir Bilim Olarak Tasavvuf: Pratikten Teoriye Tasavvufun Çelişkisi
}

\section{Ekrem Demirli' (1)}

\section{Geç Kalmış Bir İlim: İki Kimlikli Olmanın Açmazları}

Din bilimleri arasında gelişim süreci en şaşırtıcı ve çelişkili seyir takip edeni hiç kuşkusuz tasavvuf olmuştu. Öyle ki geçmişte ve günümüzde birçok insana göre tasavvuf hâlihazırda bile bir bilim olarak teşekkül etmemiştir. Bu meyanda tasavvufun fikh-1 bâtın veya bir ahlak ilmi olduğuyla ilgili iddiaları sûfîler arasında anlam bulan iddialardı. Tasavvufun gelişim seyrindeki sorunları hem kendi dâhilinde hem öteki din bilimleriyle ilişkisinde fark edebiliriz: Tasavvufun bir bilim olmaktan daha çok bir tepki ve eleştiri şeklinde gelişen yapısı bütün dönemlerde varlığını göstermiştir. Öteki din bilimleri için genellikle tasavvuf bilimden daha çok tanımını ve sınırlarını kestiremeyeceğimiz bir hâl, zevk ve en çok da zahitlik idi. Tasavvuf denilince din bilimleri arasında sistematik yapıya sahip bilimden ziyade züht hareketinden söz etmek yaygın tutumdur. Haddizatında bu bakış açısı bütün dönemlerde sürmüş, tasavvufun din bilimi haline geldiği üçüncü asrın sonlarından itibaren bile, tasavvuf bilim sayılmamıştı. Bunun en önemli nedeni tasavvufun ilgi alanını teşkil edebilecek müstakil alanın kabul edilmemiş olmasıydı. Tasavvufa bilimler arasında 'alan açmak' öteki bilimlerin özellikle de fikıh-kelamın yetersizliği kabul etmek demekti ki, bu kendi içinde bir çelişki idi. Bu meyanda tasavvufun alanını ahlak sayarsak din bilimleri arasında ahlakın bir bilim haline gelip gelemeyeceğini ortaya koymak gerekirdi. Ancak mesele sadece bu yönden izah edilemez: Din bilimlerinin gelişim seyrini iki ana akım dâhilinde mütalaa edersek sorunun ciddiyeti daha iyi fark edilebilir.

Din bilimleri erken dönemden itibaren ehl-i rey (akılcılar) denilen ve dinî metinleri yorumlamada kıyası bir yöntem olarak kullanan ekol ile ehl-i hadis denilen ve akl1-kıyası kabul etmeyen ekol olmak üzere iki ana geleneğe bölündü. Burada sistematik olarak ayrım

\footnotetext{
* Sorumlu Yazar: Ekrem Demirli (Prof. Dr.) İstanbul Üniversitesi, ilahiyat Fakültesi, Temel İslam Bilimleri Bölümü, İstanbul, Türkiye. E-posta: krmdemirli@gmail.com ORCID: 0000-0001-9063-846X 
tespit etmek her zaman mümkün olmasa bile, ekollerin imamları ve literatür tebarüz ettikçe ayrışmalar da kurumsallaştı. Öyle ki artık aşılamayacak engeller ortaya çıkmaya başlamıştı. Nihayetinde Mutezile kelamının sistematik gelişmesiyle birlikte, ehl-i rey güçlenerek bir yandan dil bilimlerinde öte yandan din bilimleri alanında teoriler ortaya attı. Onun karşısında Ehl-i sünnet hadis ekolleri ile görece akılcı hareket eden kelam ekolleri sıralandı. Burada din bilimleri fikıh ve kelam ile bu alanlara katkı sağlayan dil bilimlerinden ibaret idi. Buna mukabil ehl-i hadis veya rivayet kanadı zaten boşluk kabul etmiyor, hadislerin yoruma ihtiyaç bırakmadan hüküm ve bilgi taşıdıklarını düşünüyorlardı. Ortada herhangi bir boşluk yoktu: $\mathrm{Bu}$ itibarla bir yanda gelişmiş ve sistematik bilgi anlayışı yoktu ki tasavvufu dışarıda bıraksın; ötekinde ise bir boşluk yoktu ki tasavvufa yer ayırsın. Bunun neticesinde tasavvufun sonraki seyrinde bile kendine meşru yer bulamadı.

Din bilimlerinin meselesi sadece tasavvuf ile ilgili değildi. Bu meyanda onların arasındaki çelişkiler ve çatışmalar hiç eksik olmamıştı. Mezhepler arasındaki çatışmalar veya fikıh ile hadis arasındaki gerilimler menfi istikamette gelişti. Bununla birlikte literatür ortaya çıktıkça öteki bilimler kendilerini kabul ettirmişken tasavvuf hiçbir zaman kendini bilim disiplini olarak kabul ettiremedi. Bu durum dıştaki nedenler ile ilgilidir. Tasavvufun ana sorunu ise içerdeki durumla ilgiliydi. Tasavvufun bizzat kendisinden doğan nedenler onu bir bilim olarak kabul etmenin önünde ciddi engeller teşkil ediyordu. Bu itibarla hiçbir bilim tasavvuf kadar kendini tartış11ır kılmamıştır; buna yol açan bizzat sûfîler idi. Ebû Nasr es-Serrâc'ın (ö. 378/988) ünlü eserinde dile getirdiği 'tasavvufu ya çok överler veya çok aşağılarlar' tespiti hemen bütün dönemleri için geçerli ve hâkim bir görüştü. Bu bakımdan tasavvufun gelişim seyri çelişkiler barındırmıştı.

Meselenin ayrıntısı bir yana tasavvuf en azından öteki bilimlere göre geç teşekkül etmiş bir bilim oldu. Buna bağlı olarak tasavvufun literatürdeki yeri sınırlı kaldığı gibi hiçbir zaman kendine esaslı bir yer de bulamamıştır. Mesele erken dönemdeki tabakat, tasnif literatürü için böyle olduğu gibi modern çalışmalarda da durum değişmemiştir. Bunun başlıca nedeni tasavvufun bilime yönelik eleştirileridir. Bunu Hücvîrî’nin (ö. 465/1071) ve başka yazarların eserlerinden fark edebiliriz. Hücvîrî eserine bilimin ispatından (isbâtü'l-ilm) söz eden bölümle başlarken sûfîler ile sofistler arasındaki benzeşmeden şikâyet eder. Bu konu tasavvuf tarihinde pek tartışılmış bir konu değilken bilebildiğimiz kadarıyla sadece Bîrûnî (ö. 453/1061) bilge anlamına gelen ve sofist ile aynı köke sahip olan "sophos" ile sûfî kelimesi

1 Ebû Nasr es-Serrâc et-Tûsî, el-Lüma', nşr. Muhammed Edîb el-Câdir (Ammân: Dâru'l-feth, 2016), 7 . 
arasında irtibat olacağını ileri sürmüştü. ${ }^{2} \mathrm{O}$, kelimenin kökeninin sophos ile aynı kökten ileri gelebileceğini söyler, fakat Hücvîrî’nin dile getirdiği şeylerden söz etmez. Hücvîrî, sûfîlerin bilgi eleştirileri ile sofistlerin eleştirilerinin benzerliği sebebiyle arada tedahül yaşandığını söylemiştir. Bunu doğru bulmaz, böyle bir zannın yayıldığından şikâyet eder. Özellikle İran'ın bazı bölgelerinde bu karışıklık daha fazla olmuş, sûfîler sofistlerle bir mütalaa edilmişlerdir. ${ }^{3} \mathrm{Bu}$ tespit daha sonra İbn Haldûn'un (ö. 808/1406) eleştirilerinde de varlığını sürdürmüştür. ${ }^{4}$ Bu tespit gerçekten çok önemlidir, çünkü tasavvufun gelişim seyrinin en önemli kısmı bilim eleştirilerinden beslenir. Tasavvuf daha sonra kısmen değineceğimiz üzere bilim eleştirisi olarak gelişmişti. Bu meyanda zahitliğin zenginlik ve sosyal hayat ile eleştirilerine göre daha kalıcı bir eleştiriden söz ediyoruz. Sûfîler bilgi-amel ilişkisinde amelsiz bilginin anlamsız olacağını söyleyerek ciddi bir bilgi eleştirisi yapmışlardı. Tasavvuf içerisinde ilahi aşk anlayışının gelişmesi de bununla ilgilidir. Bu bakımdan tasavvuf tarihi ‘bilgi-eylem’ ilişkisi üzerinden kurulabilecek kadar çok malzeme vardır. Hücvîrî'nin söylediğinden anlaşılan, bunun ve başka nedenlerin etkisiyle sûfîler ile sofistler arasında benzerliğin kurulmuş olmasıydı. Bu nedenle söz konusu benzerliğin genel bir kanaat haline geldiğini de söylemek gerekir. Tasavvuf denilince bilgi, akıl, lafız eleştirisi akla gelmeye başlanmış olmalıdır. Hücvîrî eserine 'bilginin ispatı' bahsiyle başlayınca sorun çözülmüş olmadı: Bu kez tasavvuf içinde ikiye bölünerek daha bilimsel ve nazari olan kanat ile bir ameliye ve riyazet olarak üstünlüğünü -daha çok da ayrıcalığını- korumak isteyenlerin her zaman varlığını göstermeyen çatışmaları ortaya çıktı. Birinci kanat 'ibahilik' ile mücadele edebilmek için tasavvufun din bilimi haline gelmesini savunuyordu, ötekiler ise bilim haline geldiğinde tasavvufun 'soru-cevaba' döneceğini iddia ediyordu. Bu itibarla tasavvuf hem dâhili nedenlerle hem harici amillerin etkisiyle literatürü ortaya çıktığı dönemde bile yeterince hüsnükabul görmemiştir. Bu durum, yani tasavvufun sürekli hüsnükabul arama isteği tasavvuf metinlerini savunmacı bir üslupla malûl ve akim bırakmıştır. En azından bir kısmında bu durum ciddi sorunlara yol açar. Biz gerçekte tasavvufun hakiki görüşü nedir, bunu merak ederiz. Bu meyanda söz gelişi Cüneyd-i Bağdâdî (ö. 297/909) sonrasındaki metinlerde bu durum kendini daha bariz bir şekilde gösterir. Serrâc, Ebû Tâlib el-Mekkî, Ebû Bekr el-Kelâbâzî ve Abdülkerîm el-Kuşeyrî gibi yazarların eserlerinde savunmacı yaklaşım ciddi ölçüde yüzeyselleşmeye yol açar. Savunmacı üslubun etkisi altında daha dikkate değer olan ise tasavvuf tarihinde sûfî tabakatının ve literatürünün seyridir.

2 Bîrûnî, Tahkîku mâ li'l-Hind (Beyrut: Âlemü'l-Kütüb, 1983), 27-28. Bîrûnî’nin görüşlerinin ayrıntılı bir tahlili için bkz. Ali Sâmî en-Neşşâr, Neş 'etü'l-fikri'l-felsefí fi'l-İslâm (Kahire: Dâru'l-ma'ârif, 1977), III: 43-53.

3 Ali b. Osman el-Hücvîrî, Keşfü'l-mahcûb, nşr. İs'âd Abdülhâdî Kandîl (Kahire: 1974), 203-213.

4 İbn Haldûn, Mukaddime, trc. Süleyman Uludağ (İstanbul: Dergâh Yay., 2018), 849 vd. 
Tasavvuf tarihinin bilimler arasında nasıl seyrettiğini anlayabilmek için tabakat literatürünü hesaba katmak gerekir. Tabakat literatürü en azından metinler ölçüsünde öteki bilimlerde de mukabili bulunan alandır. Biz fikıh veya kelam veya başka bir alandaki tabakat literatürünü tahlil edersek genel itibarıla gerçek veya gerçeğe yakın bir tarih buluruz. Bu gerçek tarih bilgisi bize bilim yapmamızın zeminini verirken aynı zamanda hepsi belli ölçülere bağlı kalır. Bu noktada bir tabakat eserinden bekleyeceğimiz cevaplar şu soruların cevaplarıdır: Herhangi bir âlimin öncelikle biyografik ve künye bilgilerini olabildiğince doğru vermelidir. Bunların basında söz konusu âlimin doğum ölüm tarihlerinden başlayarak hayat hikâyesi hakkında az çok sahih bilgi vermiş olmalıdır. İkincisi ise okuduğu ve dâhil olduğu bilim geleneği hakkında bilgi verilmelidir. Haddizatında tabakat kitabı yazmanın gayesi de budur. Kişinin bilim silsilesi ve hocaları ve talebeleri hakkında bilgi vermek için tabakat kitabı yazılır. Üçüncüsü ise yetiştirdiği talebeler veya ondan bilgi alanlardan söz edilebilir. Son olarak yazdığı eserlerden söz edilir. Bütün bunlarda tarihsel bilgiler verilecektir ve bu bilgilerin başka kaynaklarla teyit edilebilir olması beklenir. Tasavvufun mahiyetini anlayabilmek için sûfîlerin tabakat kitaplarına bakmak yeterlidir; orada tabakat hiç de böyle olmamıştır. Başından beri sûfîler tabakat kitaplarını yazarken başka gayeler güttüler. Onlar için mesele Hz. Peygamber'e kadar varan sahih bir silsilenin tespiti idi. Bu sayede onlar tasavvufun farklı dönemlerde ve nesillerce nasıl anlaşıldığını, sahih bir züht ve ibadet hayatının nasıl geliştiğini göstermek için tabakattan yararlanmak istediler. $\mathrm{Bu}$ itibarla tabakat yazıcıllğı nazariyenin parçası olarak ortaya çıkarken tarihsel veriler ikincil hale geldi. ${ }^{5}$ Bunun belli başlı nedenleri de tespit edilebilir: Her şeyden önce sûfî tabakâtı nadiren eser yazanlar üzerine kuruludur. Başka bir anlatımla tasavvuf tabakatı daha çok ümmilerin veya bilim yapma niyeti ve kabiliyeti olmayanların hayat hikâyelerini anlattığ 1 için haklarında verilen bilgiler derme çatma bilgilerdir. Öte yandan onlar ancak belirli bir seviyeye ulaşınca bilinen-tanınan kimselerdi ve hayatları hakkındaki hikâyeler toplama bilgilerden öteye gitmezdi. Bu nedenle eserler tabakat kitabı olmaktan çok menkıbevi eserler haline geldi. Bu durumda tabakat kitabında bir ismin künye bilgileri verilse bile bunlar ya hatalıdır veya eksiktir. Eserleri ise genellikle yoktur. Çünkü çoğunun eseri yoktur. Tabakat kitabı eserler yerine 'sözler' ve kerametler anlatmakla yetinir. Çünkü ümmi sûfîlerin sözleri onların asarı kabilinden sayılır. Zaten bu eserlerin yazılma nedeni de budur: önceki nesillerden 'delil' getirmekle tasavvufu zapturapt altına almak. Tasavvuf tabakatı 'icma' delili aramaktan ortaya çıtı. Ebû Abdurrahman es-Sülemî’nin (ö.

5 Tasavvufta tarih yazıcılığının erken dönemi hakkında daha ayrıntılı bilgi ve değerlendirme için bkz. Jawid A. Mojaddedi, The Biographical Tradition in Sufism: The Tabakat Genre from al-Sulami to Jami (Richmond: Curzon Press, 2001). 
412/1021) Tabakâtu 's-sûfiyye'si ${ }^{6}$ veya Ebû Nuaym el-İsfahânî’nin (ö. 430/1038) Hilyetü'l-evliyâ's 's ' bu bakımdan dikkate değerdir. Bu eserler daha çok 'velilerin menkıbelerini' ve ibadet hayatlarını anlatarak tasavvufa çekidüzen verme niyetindeki eserlerdir. Bütün dönemlerinde tasavvufu takip edebileceğimiz en önemli metinler bu menkıbevi tabakat literatürüdür.

Bütün bunlar, tasavvufun herhangi bir bilim tasnif eserinde veya genel olarak literatürde daha önemsiz hale getirmiştir. Haddizatında Fuat Sezgin' in eserinde de görülün budur. Bununla birlikte Sezgin'in eserinde tasavvufa ayrılan yer üzerinde bazı tespitler yapmamız mümkündür.

\section{Fuat Sezgin'de Tasavvuf: Emevîler ve Abbasîler Devri Züht Hareketleri ve İlk Eserler}

Sezgin'in eserinin birinci cildinde erken dönemden başlayarak çeşitli sûfî yazarlar ve eserlerinden kısa bilgiler verilir. ${ }^{8} \mathrm{Bu}$ meyanda tasavvufun nasıl başladığg ve ilk isimlerin kim olabileceği meselesi gerçekten büyük bir sorundur. Bunun iki temel nedeni vardır: Birincisi tasavvufun bir züht hareketi ve hayatı şeklinde öteden beri var olmasıdır. Bu yönüyle tabakat yazarları $\mathrm{Hz}$. Peygamber'den başlayarak tasavvufa köken bulurlar. Bu durumda başlayanın ve var olanın tasavvuf ile irtibatını tespit etmek her zaman kolay değildir. İkinci mesele ise din bilimleri arasında ayrışmanın ortaya çıkma nedenlerini tam olarak bilemiyoruz. Özellikle tabiin neslinden birçok kişi bütün disiplinler için 'müşterek imamlar' nesli idi. Birçok kişi hem fikıh, hem hadis hem de öteki din bilimleri için imam sayılır. Bu durumda ayrışmanın nasıl olduğunu tespit etmek güçtür. Başka bir anlatımla müşterek imamlar neslinden sonra ayrışmanın ne zaman başladığını bilemediğimiz için mebde' hakkında çelişkili hükümler veririz. Aşağı yukarı tasavvufun ikinci asra doğru başladığı genel bir kabuldür. Bunu modern çalışmaların bir kabulü olarak söylemek gerekir; çünkü tasavvufu din bilimleri arasında tedvin etmek isteyen eserlerde -Ebu Nasr esSerrâc'dan itibaren- 'başlama' sözü bir yanılsama olarak görülür. Tasavvuf her zaman var idi ve her neslin ideal insanları sûfîlerdi. Fakat dönemler içerisinde tasavvuf yeni isimler kazanmış, bu nedenle tasavvuf ve ideal nesil ötekilerden ayrışarak gözle görünür hale gelmiştir. Bu nedenle tasavvuf tarihinin başlangıcı düşüncesi modern bir iddiadır. Modern araştırmalarda ise tasavvufun erken döneminde daha çok züht hareketleri üzerinde durulur. Yeni dönemlerde züht ile tasavvuf arasındaki

6 Ebû Abdurrahman es-Sülemî, Tabakâtu 's-sûfiyye, thk. Nureddin Şerîbe (Halep: Dâru'l-kitâbi'nnefîs, 1986); a.mlf., Tabakâtu's-sûfiyye = İlk Zâhid ve Sûfiler, trc. Abdurrezzak Tek (Bursa: Bursa Akademi, 2018).

7 Ebû Nuaym el-İsfahânî, Hilyetü'l-evliyâ ve tabakâtü'l-asfiyâ (Beyrut: Dâru'l-fikr, 1996), I-X.

8 Fuat Sezgin, Geschichte des Arabischen Schriftums (GAS) (Leiden: Brill, 1967), I: 629-676. 
ilişkiler kesin olarak saptanamamış olsa bile, zahitliği genel olgu olarak kabul ederek tasavvufu genel olgudan daha özel bir ayrışma saymak yaygın tutumdur. Haddizatında tasavvuf tarihinde böyle bir ayrıma gitmenin birtakım zaruretleri vardır. Her şeyden önce züht ile tasavvuf arasındaki bazı karşıtlıklar vardır. Bu meyanda züht genel anlamda Müslüman toplumda yaygın bir hareket olarak ortaya çıkmıştır. Nitekim sonraki gelişmeler olmasa zahitlik ile tasavvufu ayrıştırmak belki zorunlu sayılmayabilirdi. Zahitlik ile tasavvufu ayrıştırmanın en önemli yönü teorik ve bilimsel gelişmelerin yaşanmış olmasaydı. Aslında tasavvuf içinde haller ve makamlar üzerinde konuşmaların başlamasıyla birlikte daha iddialı cümleler ortaya çıkmaya başladı. Bu bakımdan tasavvufun hakiki başlama tarihini ne orada ne burada aramak beyhudedir: Haller ve makamlardan bahsedildiğinde tasavvuf hakiki anlamıyla ortaya çıkmış demekti. ${ }^{9} \mathrm{Bu}$ süreçte sûfîler zahitliğin yeterli gelmeyeceği birtakım görüşleri dile getirmeye başladılar. Serrâc içinde zühdün de bulunduğu bazı ahlakın sûfîleri ifade etmede yeterli olmayacağını söyleyerek 'sûfî' isminin bir yetersizlikten, daha doğrusu yeterli isim bulamamaktan kaynaklandığını söyler. ${ }^{10}$ $\mathrm{Bu}$ bahiste daha sonra şatahat diye tabir edilen birtakım düşünceler ortaya çıksa bile, haller ve makamlar düşüncesinin ortaya çıkmasından sonra tasavvufu genel züht hareketinden -veya bir hareket demek doğru olmayacağından, Müslümanlar arasındaki zahitlerden demek gerekir- ayrıştırmak zorunlu oldu. Her şeye rağmen sûfî tabakat eserleri bu ayrıştırma ve dönemlendirmeyi önemsemezler. Onlara göre başından sonuna kadar tasavvuf ibadet ve züht üzerine kurulu sahih bir silsiledir. Fuat Sezgin züht hareketlerinin kaynağı olabilecek eserler arasında ilk olarak Hasan el-Basrî’nin (ö. 110/728) risalesine dikkat çeker. ${ }^{11}$

Sezgin, Hasan el-Basrî’nin ilk zahitlerden sayılması üzerinde durur. Züht ile tasavvuf arasındaki ilişkileri tespit bir sorun olmakla birlikte, erken önemdeki yönelimi züht olarak nitelemek makul görünmektedir. Bunun birkaç nedeni var: Her şeyden önce tasavvuf veya sûfî isminin kullanılmamış olmasını dikkate almamız lazımdır. Tasavvuf ismi bütün bilimler arasında en yabancı isim sayılır. Her bilim hadislerde veya ayetlerde kendinden söz eden bir kelime bulurken tasavvuf isminin sonradan çıktığında neredeyse ittifak vardır. Daha sonra da bu ayrım ciddi bir mesele haline gelecektir. Züht ile tasavvuf arasındaki farklar nedir veya zühdü tasavvuftan nasıl ayrıştıracağız meselesi üzerinde Sezgin tespitte bulunmaz; fakat isimler sebebiyle ilk yazarları zühhâd veya zahit saymamız gerektiğini söyler. Bu

9 Konu hakkındaki ayrıntılı değerlendirmeler için bkz. Ekrem Demirli, "Tasavvuf Araştırmalarında Dönemlendirme Sorunu: Din Bilimleri ile Metafizik Arasında Tasavvurun İlim Olma Mücadelesi”, Nazariyat: İslâm Felsefe ve Bilim Tarihi Araştırmaları Dergisi, no.4 (2016): 1-29.

10 Serrâc, el-Lüma', 31-34.

11 Sezgin, GAS, I: 631-633. 
meyanda Hasan el-Basrî’nin bazı mektupları ve risalelerinin züht hakkında bilgiler içerdiğine dikkatimizi çeker. Bahsedilen mektupların aidiyeti tartışmalı olsa bile tasavvuf literatüründe Hasan el-Basrî’nin bazı sözleri ve mektuplarından söz edilir. $\mathrm{Bu}$ meyanda en azından literatürde böyle bir durumun varlığını görmemiz lazımdır. Mesela Hücvîrî, Hasan el-Basrî'nin mektubundan söz edenlerden biridir. Öyle anlaşılıyor ki Hasan el-Basrî’nin cümleleri ve hayat tarzı sonraki sûfîler arasında onun imam kabul edilmesinin nedeni idi. Bu meyanda birçok tasavvuf kitabı Hasan el-Basrî’nin sözlerinden iktibaslar içerir.

Tasavvuf tarihinde Hasan el-Basrî'ye atıf yapılan konuların başında bilgi-fıkıh eleştirisi mühim yer tutar: Onun fakih tanımı ve fikıh ile ahlak arasında kurduğu irtibat, tasavvufun bilim eleştirisinin ilk örnekleri sayılabilir. Bu eleştiriyi zamanla birçok sûfîde göreceğiz. En sonunda Cüneyd-i Bağdadî meşhur mektuplarında fikıh eleştirisini benzer cümlelerle yapacaktır. Demek ki ilk nesilden itibaren fikıh hakkında birtakım tartışmalar olmuştu. Hasan el-Basrî'nin sözü şöyle aktarılır: İnsanlar Hasan'a birini övüp fakih olduğunu söylediklerinde 'Siz hiç fakih görmemişsiniz!' demiş, ardından fakihin dünyaya ahireti tercih eden kimse olması gerektiğini söylemiştir. ${ }^{12} \mathrm{Bu}$ cümlenin İslam'ın yeni sürecinde -Doğu Akdeniz'e intikal süreci- bilim ve ahlak arasındaki tartışmalarda ehemmiyetli bir cümledir. Hasan el-Basrî'nin birçok kişi gibi temelde bu nokta üzerinde odaklandığını söylemeliyiz. Üstelik onun risalesinde cebrîlik eleştirisi de bir ahlak meselesi olarak ortaya çıkar. Bu noktada Mutezile'nin gelişiminde ahlakın ve bilgi-eylem ilişkisinin belirleyici rolü olması önemlidir. Hasan el-Basrî’ye nispet edilen Kader Risâlesi’nin Mutezilî bağlamda okunmasıyla züht arasında irtibat vardır. Risale -söylendiği gibi- cebrîlik karşısında imanda ve amelde insanın rolünü müdafaa etmek üzere yazılmışsa -ki bunu söyleyebileceğimiz birçok neden vardır- bu durum zühdün gelişmesiyle ilgilidir. Çünkü zahitlik yoğun bir ibadet ve züht hayatı üzerine kurulu idi. İlk zahitlerden itibaren ortaya çıkan temel eleştiriler ameli olmayan bilginin anlamsız olacağı idi. Hasan el-Basrî̀nin fakih tanımı da bunu gösterir: Bilginin amel ile irtibatı zahitlikle uyumlu bir düşüncedir. Gerçek fakih bilgiye sahip olan değil, bilginin gereği olarak, amel ve ahlaka sahip olan kişidir. Hasan bunu ahireti dünya hayatına tercih etmek şeklinde ifade etmişti. Belki tasavvuf tarihini yazabileceğimiz en önemli ilkelerden birisi budur. Hemen bütün sûfîlerde ameli olmayan bilginin anlamsızlığı vurgulanmıştır. Cüneyd bir âlim ile konuşmasında ona necat yolunu anlatırken amel ve ahlaklanma üzerinde durur. Sözlerine olumlu karşıllık verince ‘İşte simdi gerçek fakih oldun' dediğinde Hasan el-Basrî'nin bu cümlesinin tekrar ortaya çıktığını görmüş oluruz. Böylece biz züht hareketlerinin başlama noktası olarak Hasan el-Basrî’nin vaazlarını ve

12 Serrâc, el-Lüma', 26. 
benzer kişilerin zahitlik üzerindeki konuşmalarını kabul edebiliriz. Bütün bunlar, daha sonraki eserlerde görüldüğü kadarıyla, yeni bir bilgi anlayışının eleştirisi üzerine kurulu cümlelerdir.

Sezgin, Hasan el-Basrî’nin sonraki züht hareketi içindeki durumunu anlatırken onun sekiz zahitten birisi olarak kaynaklarda zikredildiğini söyler. Bu isimleri de zikreder ki, bunların en önemlisi Üveys el-Karenî veya Veysel Karânî’dir. Sezgin, Hasan el-Basrî̀nin eserinden başka Ebû Müslim el-Havlanî’nin (ö. 62/681-82) zühde dair bir defterinden bahseder ve şunu söyler: "Ebû Hâzim Seleme b. Dînâr ve Malik b. Dînâr'n Sahîfe fi z-zühd isimli bir eser, Şî̂ literatüründeki oldukça eski bilgiye göre Zeynelâbidîn Ali b. Hüseyin tarafından telif edilmişti. Bilinen en eski ve daha uzun zühd şiirlerine ise ilk defa Hasan el-Basrî'den sonraki nesilde, örneğin Sâbık b. Abdullah el-Berberî’ de yer alır.”'13 Fuat Sezgin bu konuda küçük, fakat önemli sayılabilecek birçok bilgiyi aktarmıştır. Hiç kuşkusuz tasavvuf tarihi yazımında bu bilgiler birbirine eklenerek çok önemli boşlukları doldurabilir. Sezgin, züht eserleriyle ilgili başka bilgiler de vermektedir ki, bunların önemli bir kısmı hadisçilerin züht eserleri sayılabilir. Bu eserlerle tasavvuf arasındaki irtibat henüz yeterince çalışılmış değildir. Özellikle sünni tasavvufun teessüs evresinde bu metinlerin belirleyici rol oynadığını söylemek gerekir. Sezgin muhaddislerin söz konusu isimlerin eserlerini ve sözlerini topladığından söz eder. Bunun yanı sıra İbn Sîrîn'den (ö. 110/729) söz etmesi önemlidir. ${ }^{14}$ Çünkü onun rüya tabirciliği sonraki tasavvufun gelişiminde rol oynamış olmalıdır.

Fuat Sezgin'in az çok bilgi verdiği isimlerden birisi ise Hallâc ve onun eserleridir. ${ }^{15}$ Bu dönemde nispeten tasavvuf daha belirgin bir hale gelmiş, birçok isim öne çıkmış, farklı şehirlerde farklı tasavvuf telakkileri yayılmaya başlanmıştır. Hallâc-1 Mansûr hakkında az çok oryantalist çalışmalarda yer alan bilgilerden hareketle bazı tespitler vardır. Bunların başında biyografisi hakkında verdiği bilgiler gelir: Hallâc sekiz sene hapis yatmış, daha sonra zamanın halifesinin annesinin himayesi ile çıkmıştır. Çeşitli sözleri sebebiyle Hallâc'a yönelik tepkiler artmış, idamıyla neticelenen birtakım ithamlarla karşılaşmıştır. Hallâc'ın idam edilmesi hiç kuşkusuz onun görüşlerinin ekol haline gelmesinde önemli rol oynamıştır. Bundan daha önemlisi ise Hallâc'ın öldürülmesi ile birlikte başlayan birtakım hadiseler tasavvufun zamanla ikircikli bir dil kullanılmasında etkili olmuştur. Bunu kendisinden sonraki sûfîler dile getirmişlerdir. Onların söylediğine göre Hallâc'ın ölümü sûfîler üzerindeki baskıları daha artırmıştır. Hadisenin akabinde ortaya çıkan baskılar tasavvufun ciddi

13 Sezgin, GAS, I: 632.

14 Sezgin, GAS, I: 633-634.

15 Sezgin, GAS, I: 651-653. 
ölçüde iletişim imkânlarının daralmasına yol açmıştır. Cüneyd'in bile bu baskılardan etkilendiği ve tedbirli hareket etmeye başladığını biliyoruz. Mesele sadece onların yaşadıkları baskılarla sınırlı da değildi. Tasavvuf kendi içinde ciddi çatışmalar ve bölünmeler yaşıyordu. Bunların bir kısmını daha sonraki eserlerden takip edebiliriz. Başta tevekkül ve rıza bahisleri olmak üzere, tasavvufun iddialı bir dil kullandığ 1 görüşler genel bir hoşnutsuzluk ortaya çıkarıyordu. Tevekkülün tasavvufun başat meselesi haline gelmesi ve rıza ile özdeşleşmesinin ciddi sorunlara yol açması kaçınılmazdı. Burada rıza üzerinden ortaya çıkan sorunlar tasavvuf ile cebrîlik arasındaki yakınlığı güçlendirmiş olmalıdır. Rıza kavramı Allah'ın yaptığı her işi rıza ve tevekkülle karşılamayı iktiza ediyordu. Tevekkül ile rıza birleştiğinde ise insanın iradesini ortadan kaldırarak tam bir teslimiyete ulaşması hedefleniyordu. Bireysel olarak değerli görülebilecek bu tavır yaygınlaştığında ciddi sorunlar ortaya çıkmış olmalıdır. Bunlara karşı1ık tasavvuf içinde tevekkülü çalışma hayatı ile dengelemek rızayı bir hal sayarak onu gaye olmaktan çıkarmak şeklindeki düşünceler tasavvufu bölmüş̧ü. Bu bölünme zaman içinde şatahat tabirinin gelişmesiyle birlikte başka bölünmelere de yol açmıştır. Biz artık tasavvuf içinde heretik, zındık, hulûlî gibi tasavvuf ile bağdaşmayan aşırı akımların zikredildiğine şahit oluyoruz. Tasavvuf içinde 'sahih-batıl' ayrımını belirginleştiren şey, nazariyenin gelişmesiydi. Böylece tasavvuf başından reddettiği bir şeye yönelmek zorunda kaldı: din bilimleri! Din bilimlerinden birisi haline gelmekle tasavvuf ilk başta eleştirdiği bilimlerden birisi haline gelmiş oldu. Sezgin'in eserinde bu görüşlere atıf yapılmaz, fakat Ma'rûf el-Kerhî, ${ }^{16}$ Zünnûn ${ }^{17}$ ve Bâyezid-i Bistâmî ${ }^{18}$ gibi isimler bu süreçte çok önemli rol oynamış kişiler olarak eserde zikredilir. Sezgin'in eserinde yer verdiği mühim kişilerden birisi de Muhâsibî’ dir. ${ }^{19}$ Muhâsibî, Hakîm Tirmizî ile birlikte Cüneyd öncesinde en ciddi eserler yazan kişilerden birisiydi. Bu itibarla Muhâsibî Tirmizî’ye göre de daha sistematik ve daha dikkatli bir yazar sayılabilir.

\section{Sonuç Yerine}

Fuat Sezgin'in bahsi geçen isimlerle ilgili yeni bilgi vermemiştir. Ancak bazı yaklaşımları tasavvuf tarihi yazıcıllğına katkı sağlayacak niteliktedir: Bunlardan birincisi Hasan el-Basrî’nin öncülüğünde züht risaleleriyle ilgili küçük anekdotlardır. Bu anekdotların tasavvuf tarihi yazımında ciddi bir katkı sağlayacağını söylemek gerekir. Bunun yanı sıra Sezgin'in Emevî erken döneminde tasavvufun henüz bulunmadığı hakkındaki tespiti de genel kabul gören bir tespittir. Hasan el-Basrî

16 Sezgin, GAS, I: 637.

17 Sezgin, GAS, I: 643.

18 Sezgin, GAS, I: 645-646.

19 Sezgin, GAS, I: 639-643. 
ile birlikte söz konusu sekiz zahit, sonraki literatür içinde aktarılan görüşleriyle bu dönemin imamlarını teşkil eder. Öte yandan Sezgin eserleri bulunmasa bile isimleri doğru bir şekilde sıralamıştır. Bu meyanda Kerhî, Bistâmî, Zünnûn gibi isimler tasavvufun gidişatını şekillendiren kurucu isimlerdir. Bir disiplinin kurucu isimlerinin eser yazmamış olması veya yazmışsa da yitik olması kaderin bir cilvesidir. Fakat tasavvuf tarihinde vakıa böyle olmuştur: Tasavvuf ümmi imamların görüşleri üzerine kurulu bir literatür ortaya koyan tek disiplindir. Öte yandan Sezgin'in eserinde dikkat çeken bir hususa da değinmek gerekir: Tasavvuf tarihini tasavvuf tarihi eserlerinden yazmak kötü bir alışkanlıktır. Tasavvufa dışarıdan bakmadan tasavvuf tarihi yazılamaz. Bu itibarla Câhız ile ilgili referansı çok önemli bir bakış verebilir. Acaba öteki disiplinler tasavvufu ve sûfîleri nasıl görüyordu? Sûfîlerin bilim ve toplum eleştirileri nasıl karşılanıyordu? Bu soruları öteki disiplinlerde yazılan eserlerden ‘derlemedikten' sonra tasavvuf tarihi yazmamız mümkün görünmüyor.

\section{Kaynakça/References}

el-Bîrûnî, Ebu'r-Reyhâni. Tahkîku mâ li'l-Hind. Beyrut: Âlemü'l-Kütüb, 1983.

Demirli, Ekrem. "Tasavvuf Araştırmalarında Dönemlendirme Sorunu: Din Bilimleri ile Metafizik Arasında Tasavvurun İlim Olma Mücadelesi." Nazariyat: İslâm Felsefe ve Bilim Tarihi Araştırmaları Dergisi, no.4 (2016): 1-29.

el-Hücvîrî, Ali b. Osman. Keş̧ü̉ l-mahcûb. nşr. İs‘âd Abdülhâdî Kandîl, Kahire: 1974.

İbn Haldûn. Mukaddime. trc. Süleyman Uludağ, İstanbul: Dergâh Yayınları, 2018.

el-İsfahânî, Ebû Nuaym. Hilyetü'l-evliyâ ve tabakâtü'l-asfiyâ. Beyrut: Dâru'l-fikr, 1996.

Mojaddedi, Jawid A. The Biographical Tradition in Sufism: The Tabakat Genre from al-Sulami to Jami. Richmond: Curzon Press, 2001.

en-Neşşâr, Ali Sâmî. Neş 'etü'l-fikri'l-felsefí fi'l-İslâm. Kahire: Dâru'l-ma'ârif, 1977. es-Serrâc, Ebû Nasr. el-Lüma'. nşr. Muhammed Edîb el-Câdir, Ammân: Dâru'l-feth, 2016.

Sezgin, Fuat. Geschichte des Arabischen Schrifttums (GAS). Leiden: Brill, 1967.

es-Sülemî, Ebû Abdurrahman. Tabakâtu's-sûfiyye. thk. Nureddin Şerîbe, Halep: Dâru'l-kitâbi'nnefîs, 1986.

es-Sülemî, Ebû Abdurrahman. Tabakâtu's-sûfiyye = İlk Zâhid ve Sûfiller. trc. Abdurrezzak Tek, Bursa: Bursa Akademi, 2018. 